\title{
Peripherally administered antibodies against amyloid $\beta$-peptide enter the central nervous system and reduce pathology in a mouse model of Alzheimer disease
}

\author{
Frédérique Bard, Catherine Cannon, Robin Barbour, Rae-Lyn Burke, Dora Games, \\ Henry Grajeda, Teresa Guido, Kang Hu, Jiping Huang, Kelly Johnson-Wood, \\ Karen Khan, Dora Kholodenko, Mike Lee, IVan Lieberburg, Ruth Motter, \\ Minh Nguyen, Ferdie Soriano, Nicki Vasquez, Kim Weiss, Brent Welch, Peter Seubert, \\ Dale SCHENK \& TED YeDNOCK
}

Elan Pharmaceuticals, 800 Gateway Boulevard, South San Francisco, California 94080, USA

Correspondence should be addressed to F.B.; email: fbard@elanpharma.com

One hallmark of Alzheimer disease is the accumulation of amyloid $\beta$-peptide in the brain and its deposition as plaques. Mice transgenic for an amyloid $\beta$ precursor protein (APP) mini-gene driven by a platelet-derived (PD) growth factor promoter (PDAPP mice), which overexpress one of the disease-linked mutant forms of the human amyloid precursor protein, show many of the pathological features of Alzheimer disease, including extensive deposition of extracellular amyloid plaques, astrocytosis and neuritic dystrophy ${ }^{1,2}$. Active immunization of PDAPP mice with human amyloid $\beta$-peptide reduces plaque burden and its associated pathologies ${ }^{3}$. Several hypotheses have been proposed regarding the mechanism of this response ${ }^{4,5}$. Here we report that peripheral administration of antibodies against amyloid $\beta$-peptide, was sufficient to reduce amyloid burden. Despite their relatively modest serum levels, the passively administered antibodies were able to enter the central nervous system, decorate plaques and induce clearance of preexisting amyloid. When examined in an ex vivo assay with sections of PDAPP or Alzheimer disease brain tissue, antibodies against amyloid $\beta$-peptide triggered microglial cells to clear plaques through Fc receptor-mediated phagocytosis and subsequent peptide degradation. These results indicate that antibodies can cross the blood-brain barrier to act directly in the central nervous system and should be considered as a therapeutic approach for the treatment of Alzheimer disease and other neurological disorders.

We administered antibodies against amyloid $\beta$-peptide $(A \beta)$ by intraperitoneal injection to mice transgenic for an $A \beta$ precursor protein (APP) mini-gene driven by a platelet-derived (PD) growth factor promoter (PDAPP mice). In the first experiment, 8- to 10-month-old heterozygous PDAPP mice $(n=8)$ received either PBS, one of two different mouse monoclonal antibodies against $A \beta$ (10D5 or 21F12) or a polyclonal immunoglobulin (Ig) fraction obtained from mice immunized with the 42amino-acid form of $A \beta$ (pabA $\beta_{1-42}$ ). The mice received weekly injections of antibody for six months, maintaining a constant antibody serum concentration throughout the course of the experiment. We used quantitative image analysis to determine amyloid burden and enzyme-linked immunoassay (ELISA) to determine $A \beta_{42}$ levels in the cortex, as described ${ }^{3}$. Relative to control-treated mice, the polyclonal immunoglobulin fraction against $A \beta$ and one of the monoclonal antibodies (10D5) re- duced plaque burden by $93 \%$ and $81 \%$, respectively (Fig. 1 a, $\mathrm{P}<$ $0.005)$. There were similar reductions in cortical levels of $A \beta_{42}$ by ELISA measurements $(6200,4890$ and $13800 \mathrm{ng} / \mathrm{g}$ tissue for 10D5, pabA $\beta_{1-42}$ and PBS, respectively). Although 21 F12 seemed to have a relatively modest effect on plaque burden, there was no substantial reduction as determined by ELISA measurements $(13,580 \mathrm{ng} / \mathrm{g})$. The effect of pabA $\beta_{1-42}$ on plaque burden was demonstrated in micrographs of brain sections obtained from mice having the median level of plaque burden within their respective groups. Most of the diffuse deposits and many of the larger compacted plaques were absent in mice treated with pabA $\beta_{1-42}$ compared to those in the control groups.

In a second study, we repeated 10D5 treatment and tested two additional antibodies against A $\beta, 3 \mathrm{D} 6$ and 16C11 (Fig.1c). Control groups received either PBS or an irrelevant isotypematched antibody (TM2a). The experimental design was the same as in the previous study except for the age of the mice (11.5-12 months old). Once again, after 6 months of treatment, 10D5 reduced plaque burden by greater than $80 \%$ compared with that of either the PBS or isotype-matched antibody controls $(P=0.003)$. Treatment with 3D6 was equal ly effective, producing an $86 \%$ reduction in plaque burden $(P=0.003)$. In contrast, $16 C 11$ failed to have any effect on plaque burden. Unlike actively immunized mice, mice receiving exogenous antibodies against $A \beta$ did not demonstrate $a$ T-cell proliferative response to $A \beta$ when their splenocytes were examined in vitro, indicating that a T-cell response is not required for amyloid plaque clearance (data not shown). These results indicate that in the absence of T-cell immunity, antibodies against $A \beta$ peptide are sufficient to decrease amyloid deposition in PDAPP mice.

To determine whether the peripherally administered antibodies against $A \beta$ had entered the central nervous system (CNS) to act directly on plaques, we examined brain sections taken from saline-perfused mice at the end of the second study. We exposed unfixed cryostat brain sections to a fluorochrome-tagged reagent against mouse immunoglobulin. Plaques within the brains of the 10D5- and 3D6-treated groups were strongly 'decorated' with antibody, whereas there was no staining in the 16C11-treated group (Fig. 2a, top). To show the full extent of plaque deposition, we immunostained serial sections of each brain with an exogenous antibody against $A \beta$, followed by the secondary reagent (Fig. 2a, bottom). After peripheral administration, 10D5 and 3D6 had gained access to most plaques within the CNS where they 
a

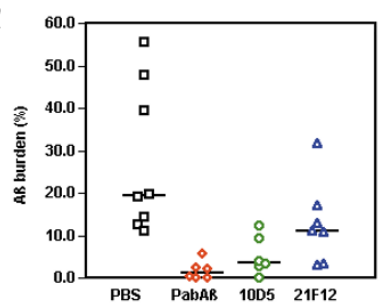

b

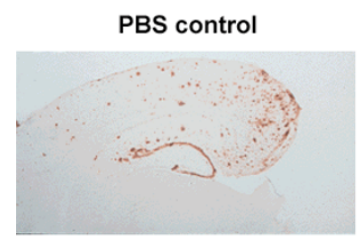

PabAß1-42 treatment

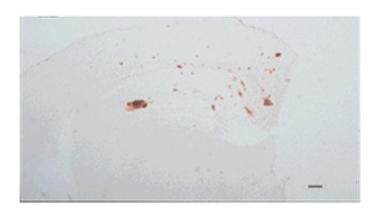

C

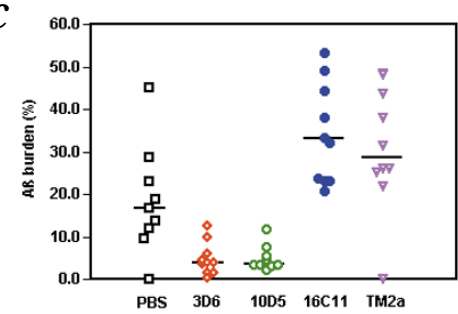

Fig. $1 A \beta$ burden in the frontal cortex of PDAPP mice is reduced after 6 months of treatment with antibodies against $A \beta$. a and $\mathbf{c}$, Percentage of frontal cortex area occupied by $A \beta$ deposits shown in individual mice sorted by treatment group ( $n=8$ ). Horizontal lines indicate median values. $\mathbf{b}$, Brain sections of the cortex and hippocampus obtained from mice with the median level of plaque burden in their respective groups. Scale bar represents $250 \mu \mathrm{m}$. may have directly triggered amyloid clearance. It is likely that $16 \mathrm{C} 11$ al so had access to the plaques but was unable to bind (described below).

We undertook a separate study to determine if antibody treatment resulted in the clearance of preexisting amyloid or simply prevented formation of new plaques. We administered 3D6 or control antibody to 13-month-old heterozygous PDAPP mice, then examined the brains for total plaque burden after 3 and 35 days of treatment. Although there was no obvious change in the number of large plaques over the short treatment period (Fig. $2 b$ ), there seemed to be a reduction in diffuse amyloid and small aggregates of $A \beta$ (Fig. 2b, inset). By image analysis of the frontal cortex, nearly $60 \%$ of the small plaques and diffuse amyloid, corresponding to pixels with intermediate to low intensity, had been eliminated during the intervening 32 days of treatment (Fig. 2c; $P=0.001$ ). These results confirm that the antibody treatment triggered clearance of preexisting amyloid.

To further examine the effect of antibodies on plaque clearance, we established an ex vivo assay in which primary microglial cells were cultured with unfixed cryostat sections of either
PDAPP mouse or human Alzheimer disease (AD) brains. After 24 hours, we fixed, permeabilized and immunostained the cultures to follow the fate of amyloid $\beta$-peptide, and visualized the exogenous microglial cells with a nuclear stain. In PDAPP brain sections assayed in the presence of $16 \mathrm{C} 11$ (one of the antibodies against $A \beta$ that was not efficacious in vivo), amyloid $\beta$-protein plaques remained intact and there was no phagocytosis. In contrast, after culture of adjacent sections in the presence of 10D5, amyloid deposits were mostly eliminated and the microglial cells showed many phagocytic vesicles containing $A \beta$ (Fig. 3a, top). We obtained identical results with AD brain sections: 10D5 induced phagocytosis of AD plaques, whereas $16 \mathrm{C} 11$ was inactive (Fig. 3a, bottom). Furthermore, the assay was equally effective with either mouse or human microglial cells, and with mouse, rabbit or primate antibodies against $A \beta$ (data not shown).

By comparison of six different antibodies tested in both systems, the ex vivo assay was predictive of in vivo efficacy (Table 1). Antibodies 10D5, 3D6 and pabA $\beta_{1-42}$ were all active in the ex vivo assay and demonstrated efficacy in vivo. In contrast, $16 \mathrm{C} 11,21 \mathrm{~F} 12$ and the control antibody TM2a were inactive in a

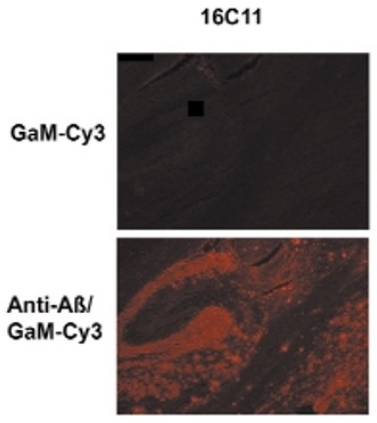

3D6

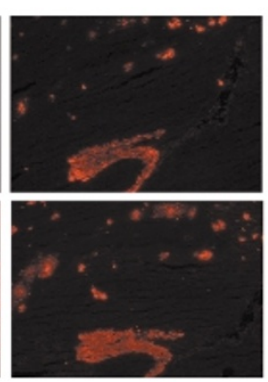

Fig. 2 After peripheral administration, 10D5 and 3D6 enter the CNS, bind to A $\beta$ plaques and trigger amyloid clearance. a, Cryostat sections of brains from treated mice were exposed directly to fluorescently conjugated goat anitbody against mouse immunoglobulin (top). Serial sections from the same brains were exposed to 10D5 before GaM-Cy3 reagent to show full extent of plaque burden (bottom). Scale bar represents $100 \mu \mathrm{m}$. Anti-A $\beta$, antibody against A $\beta$. b, Total plaque burden in the hippocampus and cortex in mice treated for 3 and $35 \mathrm{~d}$ with 3D6. The plaque burden is greatly reduced by 3D6 and 10D5 compared with that of 16C11.Scale bar represents $120 \mu \mathrm{m}$. Insets, high-powered magnification of individual large plaques within the cortex of the corresponding section (scale bar represents $20 \mu \mathrm{m}$ ). There is a lack of amyloid fibrils and small aggregates surrounding the plaque in the day-35 section. c, Quantification of diffuse amyloid and small plaques shows a $60 \%$ reduction between the 3 - and 35 -day treatment groups $(\mathrm{n}=$ 10/group; $\mathrm{P}=0.001$ ). b
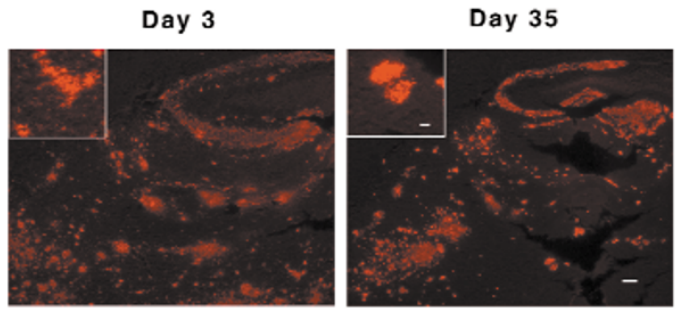

C

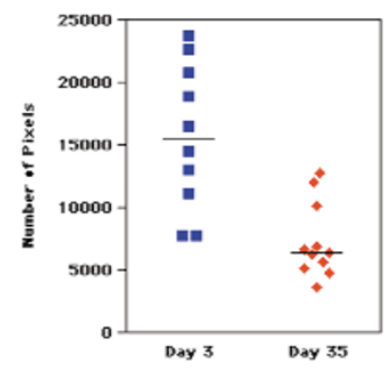


a

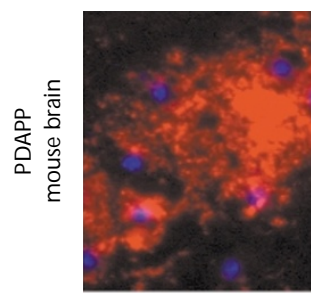

是 $\frac{\sqrt{\frac{1}{0}}}{\frac{0}{0}}$

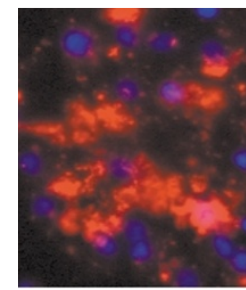

10D5
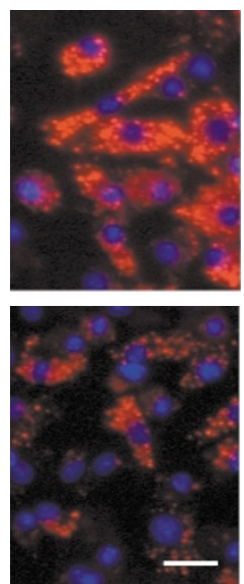

b
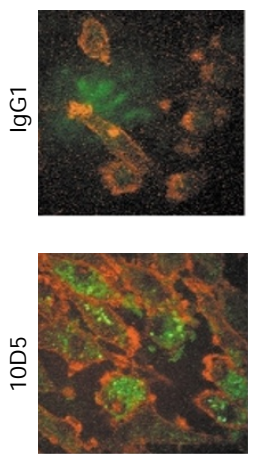
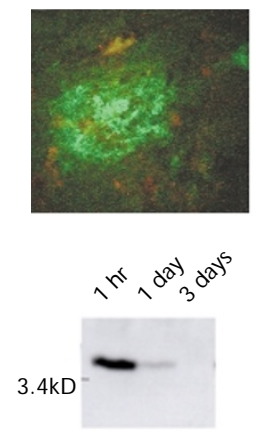

C

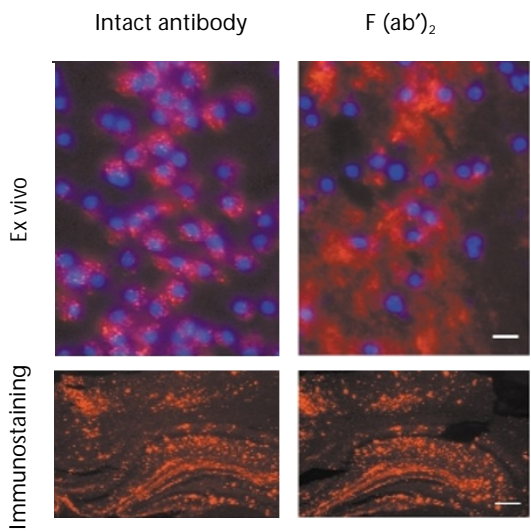

Fig. 3 Fc receptor-mediated phagocytosis of $A \beta$ in an ex vivo assay. a, Mouse microglia cultured with unfixed cryostat sections of PDAPP (top) or $A D$ (bottom) brain in the presence of antibodies against $A \beta$. In the presence of $10 \mathrm{D} 5, A \beta$ (red) localizes to vesicles within the membrane boundaries of microglial cells; in the presence of $16 \mathrm{C} 11$, plaques remain intact and there is no evidence of cellular staining. Scale bar represents $10 \mu \mathrm{m}$. b. Confocal microscopy shows that in the presence of control IgG1 (top), microglial cells (red) are in a confocal plane above the tissue section and $A \beta$ (green) remain in plaques within the tissue plane (differ- ent planes of the same field are shown here). In the presence of 10D5 (bottom left), nearly all $A \beta$ is localized within the microglial cells. Bottom right, western blot analysis with a polyclonal antibody against $A \beta$ shows complete degradation of $A \beta$ within $3 \mathrm{~d}$ (left margin, molecular size marker). c, Fc receptor-mediated phagocytosis of $A \beta$, shown by ex vivo assay in the presence of intact or $F\left(a b^{\prime}\right)_{2}$ fragments of 3D6 (top). Scale bar represents $50 \mu \mathrm{m}$. A $\beta$ plaques in consecutive sections are equally 'decorated' with intact 3D6 and its F( $\left(\mathrm{ab}^{\prime}\right)_{2}$ fragments (bottom). Scale bar represents $300 \mu \mathrm{m}$.

both assays. Comparison of other antibody characteristics showed that whereas $16 \mathrm{C} 11$ and $21 \mathrm{~F} 12$ bound to aggregated synthetic $A \beta$ peptide with high avidity, they were unable to bind to plaques in unfixed brain sections. This result is consistent with the inability of these two antibodies to decorate plaques after in vivo administration (as shown for 16C11 in Fig. $2 a$, top) and explains their inability to trigger plaque clearance. We found no correlation between antibody efficacy and affinity for soluble A 3 : 3D6 and the inactive antibodies captured soluble $A \beta$ with moderate to high affinity, whereas 10D5 could not capture the soluble peptide. These results indicate that recognition and clearance of deposited $A \beta$ is an important component of antibody efficacy in vivo and may be more important than a mechanism involving the prevention of plaque deposition by recognition of soluble $A \beta$.

We then used confocal microscopy to confirm that $A \beta$ was internalized during the course of the ex vivo assay (Fig. 3b). In the presence of control antibody, the exogenous microglial cells (red) remained in a confocal plane above the tissue section and contained no phagocytic vesicles, whereas $A \beta$ (green) remained

Table 1 The ex vivo assay as predictor of in vivo efficacy.

\begin{tabular}{|c|c|c|c|c|c|c|}
\hline Antibody & Isotype & $\begin{array}{l}\text { Avidity for } \\
\text { aggregated } \\
A \beta(p M)\end{array}$ & $\begin{array}{l}\text { Affinity for } \\
\text { soluble } \\
A \beta(n M)\end{array}$ & $\begin{array}{c}\text { Binding to } \\
A \beta \\
\text { plaques }\end{array}$ & $\begin{array}{l}\text { Ex vivo } \\
\text { efficacy }\end{array}$ & $\begin{array}{l}\text { In vivo } \\
\text { efficacy }\end{array}$ \\
\hline
\end{tabular}

monoclonal

3D6

10D5

$16 \mathrm{C} 11$

$21 \mathrm{~F} 12$

TM2a
PabA $\beta_{1-42}$

$\begin{array}{ccc}\operatorname{lgG} 2 \mathrm{~b} & 470 & <30 \\ \operatorname{lgG} 1 & 43 & \text { no capture } \\ \operatorname{lgG1} & 90 & 110 \\ \operatorname{lgG} 2 \mathrm{a} & 500 & 80 \\ \operatorname{lgG1} & - & - \\ \text { mix } & 600 & \text { nd }\end{array}$

$\begin{array}{lll}+ & + & + \\ + & + & + \\ - & - & - \\ - & - & - \\ - & - & - \\ + & + & +\end{array}$

The affinity of 10D5 was too low to capture soluble $A \beta$ and could not be measured in this assay. nd, not done. in plaques within the tissue plane (Fig. 3b, top). In the presence of 10D5, nearly all plaque amyloid was contained in vesicles within the exogenous microglial cells (Fig. 3b, bottom). This result is consistent with the earlier finding of intracellular $A \beta$ immunoreactivity within macrophage and microglial cells in the CNS of immunized mice ${ }^{3}$. To determine the fate of the internalized peptide, we assessed 10D5-treated cultures by western blot analysis (Fig. 3b, bottom right). At 1 hour, when no phagocytosis had yet occurred, reaction with a polyclonal antibody against $A \beta$ showed a strong 4-kDa band, corresponding to $A \beta$ peptide. $A \beta$ immunoreactivity decreased at day 1 and was absent by day 3 . There was no degradation of $A \beta$ staining in cultures with control IgG1. Thus, in contrast to what has been reported for $A \beta$ with other microglial scavenging pathways ${ }^{6,7}$, antibody-mediated phagocytosis of $A \beta$ led to its degradation.

To determine if phagocytosis in the ex vivo assay was mediated by $\mathrm{Fc}$, we prepared $\mathrm{F}\left(\mathrm{ab} \mathrm{b}^{\prime}\right)_{2}$ fragments of 3D6. Although the antibody fragments retained their full ability to react with plaques (Fig. 3c, bottom), they were unable to trigger microglial cell phagocytosis (Fig. 3c, top). In addition, phagocytosis induced by the whole 3D6 antibody was inhibited by antibodies specific for Fc receptors on either human or mouse microglial cells (data not shown). These results indicate that in vivo clearance of $A \beta$ occurred through Fc receptor-mediated phagocytosis.

In summary, we have shown that passively administered antibodies against $A \beta$ peptide reduced the extent of plaque deposition in a mouse model of Alzheimer dis- 
ease. Antibody entry into the CNS was not due to abnormal leakage of the blood-brain barrier, as there was no increase in vascular permeability in PDAPP mice. In addition, the concentration of endogenous immunoglobulins in the brain parenchyma of aged PDAPP mice was the same as in nontransgenic mice, representing $0.1 \%$ of the antibody concentration in serum (regardless of isotype; data not shown). Similar findings have been published for antibody levels in human cerebrospinal fluid ${ }^{8}$. These studies indicate that monoclonal antibodies are able to enter the CNS at therapeutically relevant levels, and that antibodies may be considered not only for the treatment of Alzheimer disease, but possibly for other CNS disorders as well.

\section{Methods}

Immunization procedures. Monoclonal antibodies against $A \beta$ were raised against synthetic peptide fragments derived from different regions of $A \beta$, and coupled to a carrier protein as described ${ }^{9,10}$. Polyclonal immune sera were pooled from 100 mice that had been immunized with full length $A \beta_{1-42}$, and the immunoglobulin fraction was isolated by standard ammonium sulfate precipitation. After purification, all antibodies were dialyzed against PBS and had a final endotoxin level of $<1$ endotoxin unit (EU), asmeasured by the limulus amoebocyte gel clot assay (Associates of Cape Cod, Cape Cod, Massachusetts). Antibody titers in serum were determined weekly as described ${ }^{3}$.

Ex vivo assay. Cryostat sections ( $10 \mu \mathrm{m}$ in thickness) of PDAPP mouse or human $A D$ brains (postmortem interval, less than $3 \mathrm{~h}$ ) were 'thawmounted' onto polylysine-coated, round glass coverslips and placed in wells of 24-well tissue culture plates. The coverslips were washed twice with assay medium consisting of hybridoma-serum free medium (H-SFM; Life Technologies) plus 1\% FBS, glutamine, penicillin/streptomycin, and 5 $\mathrm{ng} / \mathrm{ml}$ recombinant mouse GM-CSF granulocyte-monocyte colony-stimulating factor)(R\&D Systems, Minneapolis, Minnesota). Antibodies (control or against $A \beta)$ were added at a $2 X$ concentration $(5 \mu \mathrm{g} / \mathrm{ml}$ final) for $1 \mathrm{~h}$. Microglial cells were then seeded at a density of $0.8 \times 10^{6}$ cells $/ \mathrm{ml}$ assay medium. In some experiments, medium contained $10 \mu \mathrm{g} / \mathrm{ml}$ soybean trypsin inhibitor (Life Technologies). The cultures were maintained in a humidified incubator at $37^{\circ} \mathrm{C}$ in an atmosphere of $5 \% \mathrm{CO}_{2}$ for $24 \mathrm{~h}$ or longer. After incubation, cultures were fixed with $4 \%$ paraformaldehyde and permeabilized with $0.1 \%$ Triton-X100. Sections were stained with biotinylated 3D6, followed by streptavidin/Cy3 conjugate Jackson ImmunoResearch, West Grove, Pennsylvania). Cultures were observed with an inverted fluorescent microscope (TE300; Nikon, Melville, New York) and photomicrographs were taken with a SPOT digital camera using SPOT software
(Diagnostic Instruments, Sterling Heights, Michigan). For western blot analysis, cultures were extracted with $8 \mathrm{M}$ urea, diluted 1:1 in reducing tricine sample buffer, and loaded onto a 16\% tricine gel (Novex, San Diego, California). After transfer onto Immobilon, blots were exposed to $5 \mu \mathrm{g} / \mathrm{ml}$ pabA $\beta_{42}$, followed by horseradish peroxidase-conjugated antibody against mouse, and were developed with an ECL kit (Amersham).

Microglia culture. Microglial cells were obtained from cerebral cortices of neonate DBA/2N mice (1-3 days old). Cortices were mechanically dissociated in Hanks' balanced salt solution with $50 \mu \mathrm{g} / \mathrm{ml}$ DNase I (both from Sigma). Dissociated cells were filtered through a $100 \mu \mathrm{m}$ cell strainer (Falcon, Heidelberg, Germany) and centrifuged at $200 \mathrm{~g}$ for $5 \mathrm{~min}$. Pellets were resuspended in growth medium (high-glucose DMEM, 10\% FBS and $25 \mathrm{ng} / \mathrm{ml}$ recombinant mouse granulocyte-monocyte colony-stimulating factor), and cells were plated at a density of two brains per T-75 plastic culture flask. After 7-9 d, the flasks were rotated at 200 rpm using a Lab-Line orbital shaker with a $19-\mathrm{mm}$ orbit for $2 \mathrm{~h}$ at $37{ }^{\circ} \mathrm{C}$. Cell suspensions were centrifuged at $200 \mathrm{~g}$ and resuspended in assay medium.

Acknowledgments

We thank K. Hoenow for technical support.

\section{RECEIVED 5 JUNE; ACCEPTED 20 JUNE 2000}

1. Games, D. et al. Alzheimer-type neuropathology in transgenic mice overexpressing V717F $\beta$-amyloid precursor protein. Nature 373, 523-527 (1995).

2. Masliah, E. et al. Comparison of neurodegenerative pathology in transgenic mice overexpressing V717F beta-amyloid precursor protein and Alzheimer's disease. J. Neurosci. 16, 5795-57811 (1996).

3. Schenk, D. et al. Immunization with amyloid- $\beta$ attenuates Alzheimer-disease-like pathology in the PDAPP mouse. Nature 400, 173-177 (1999).

4. St. George-Hyslop, P.H. \& Westaway, D.A. Alzheimer's disease: antibody clears senile plaques. Nature 400, 116-117 (1999).

5. Duff, K. Curing amyloidosis: will it work in humans? Trends Neurosci. 22, 485-486 (1999).

6. Paresce, D.M., Chung, H. \& Maxfield, F.R. Slow degradation of aggregates of the Alzheimer's disease amyloid $\beta$-protein by microglial cells. J. Biol. Chem. 272, 29390-29397 (1997).

7. Chung, H., Brazil, M.I., Soe, T.T. \& Maxfield, F.R. Uptake, degradation, and release of fibrillar and soluble forms of Alzheimer's amyloid $\beta$-peptide by microglial cells. J. Biol. Chem. 274, 32301-32308 (1999).

8. Thompson, E.J. \& Keir, G. Laboratory investigation of cerebrospinal fluid proteins. Ann. Clin. Biochem. 27, 425-435 (1990).

9. Johnson-Wood K. et al. Amyloid precursor protein processing and A 442 deposition in a transgenic mouse model of Alzheimer disease. Proc. Natl. Acad. Sci. USA 94, 1550-1555 (1997).

10. Hyman, B.T. et al. Kunitz protease inhibitor-containing amyloid beta protein precursor immunoreactivity in Alzheimer's disease. J. Neuropathol. Exp. Neurol. 51, 76-83 (1992). 